bly will remain necessary to protect HCWs having close contact with infectious TB patients.

Because studies to evaluate the independent importance of respirators in protecting HCWs from TB have not been conducted and are unlikely to be conducted in the United States, the effectiveness of respirators in preventing TB transmission will remain uncertain. Our findings, in contrast to those of previous studies using different assumptions and measures, suggest that the cost of a respiratory protection program at most hospitals will not be excessive.

\section{REFERENCES}

1. Centers for Disease Control and Prevention. Draft guidelines for preventing the transmission of tuberculosis in health-care facilities, second edition: notice of comment period. Federal Register 1993;58(195):52810-52854.

2. Guidelines for Preventing the Transmission of Mycobacterium tuberculosis in Health-Care Facilities, 1994. MMWR 1994;43(RR-13).

3. Adal KA, Anglim AM, Palumbo CL, Titus MG, Coyner BJ, Farr BM. The use of high-efficiency particulate air filter respirators to protect hospital workers from tuberculosis. N Engl J Med 1994;331:169-173.

4. Nettleman MD, Fredrickson M, Good NL, Hunter SA. Tuberculosis control strategies: the cost of particulate respirators. Ann Intern Med 1994;121:37-40.

5. Fella P, Rivera P, Hale M, Squires K, Sepkowitz K. Dramatic decrease in tuberculin skin test conversion rate among employees at a hospital in New York City. Am J Infect Control 1995;23:352-356.

6. Edlin BR, Tokars JI, Grieco MH, Crawford JT, Williams J, Sordillo EM, et al. An outbreak of multidrug-resistant tuberculosis among hospitalized patients with the acquired immunodeficiency syndrome. $N$ Engl J Med 1992;326:1514-1521.

7. Pearson ML, Jereb JA, Frieden TR, Crawford JT, Davis BJ, Dooley SW, et al. Nosocomial transmission of multidrug-resistant Mycobacterium tuberculosis. A risk to patients and healthcare workers. Ann Intern Med 1992;117:191-196.

8. Jereb JA, Klevens M, Privett TD, Smith PJ, Crawford JT, Sharp VL, et al. Tuberculosis in healthcare workers at a hospital with an outbreak of multidrug-resistant Mycobacterium tuberculosis. Arch Intern Med 1995;155(8):854-859.

9. Beck-Sague C, Dooley SW, Huttun MD, Otten J, Breeden A, Crawford JT, et al. Hospital outbreaks of multidrug-resistant Mycobacterium tuberculosis infections. Factors in transmission to staff and HIV-infected patients. JAMA 1992;268:1280-1286.

10. Jarvis WR, Bolyard EA, Bozzi CJ, Burwen DR, Dooley SW, Martin LS, et al. Respirators, recommendations, and regulations: the controversy surrounding protection of healthcare workers from tuberculosis. Ann Intern Med 1995;122:142-146.

11. Sobel E. HEPA respirators and tuberculosis in hospital workers. $N$ Engl J Med 1994;331:1658-1659. Letter.

12. Chen S-K, Vesley D, Brousseau LM, Vincent JH. Evaluation of single-use masks and respirators for protection of healthcare workers against mycobacterial aerosols. Am J Infect Control 1994;22:65-74.

13. Department of Health and Human Services. Notice of proposed rulemaking on respiratory protection devices. Health-care-facility workers potentially exposed to tuberculosis (42 CFR 84). Federal Register 1994;59(99):26850-26889

14. Department of Health and Human Services. Final notice on respiratory protective devices. Federal Register 1995;60(110):30336-30404.

15. Wenger PN, Otten J, Breeden A, Orfas D, Beck-Sague CM, Jarvis WJ. Control of nosocomial transmission of multidrug-resistant Mycobacterium tuberculosis among healthcare workers and HIV-infected patients. Lancet 1995;345:235-240.

16. Stroud LA, Tokars JI, Grieco MH, Crawford JT, Culver DH, Edlin BR, et al. Evaluation of infection control measures in preventing the nosocomial transmission of multidrug-resistant Mycobacterium tuberculosis in a New York City Hospital. Infect Control Hosp Epidemiol 1995;16:141-147.

17. Maloney SA, Pearson ML, Gordon MT, Del Castillo R, Boyle JF, Jarvis WR. Efficacy of control measures in preventing nosocomial transmission of multidrug-resistant tuberculosis to patients and healthcare workers. Ann Intern Med 1995;122:90-95.

18. Kenyon TA, Ridzon R, Luskin-Hawk R, Schultz C, Paul WS, Valway SE, et al. A nosocomial outbreak of multidrug-resistant tuberculosis. Ann Intern Med 1987;127:32-36.

19. Nicas M. Respiratory protection and the risk of Mycobacterium tuberculosis infection. Am J Ind Med 1995;27:317-333.

20. Barnhart S, Sheppard L, Beaudet N, Stover B, Balmes J. Tuberculosis in healthcare settings and the estimated benefits of engineering controls and respiratory protection. J Occup Environ Med 1997;39:849-854.

\title{
TB Control Programs in US Hospitals
}

\section{Gina Pugliese, RN, MS Martin S. Favero, PhD}

Outbreaks of tuberculosis (TB) in hospitals have occurred when the Centers for Disease Control and Prevention (CDC) guideline recommendations for preventing the transmission of Mycobacterium tuberculosis were not implemented fully. Investigators from the CDC recently reported the results of a survey to determine whether US hospitals are making progress in implementing the $\mathrm{CDC}$ guidelines for preventing TB.

In 1992, a survey was conducted of all public (city, county, Veterans' Affairs, and primary medical school-affiliated) US hospitals $(\mathrm{n}=632)$ and 444 random samples (20\%) of all private hospitals with 100 beds or more. In 1996, 136 random samples
(50\%) of all 1992 respondent hospitals with six or more TB admissions in 1991 were resurveyed.

Of the 1,076 hospitals surveyed in 1992, $763(71 \%)$ respondents returned a completed questionnaire. Among these, 536 (71\%) of 755 reported having rooms that met CDC criteria for acid-fast bacilli isolation, ie, negative air pressure, six or more air exchanges per hour, and air vented directly to the outside. The predominant respiratory protective device for healthcare workers was nonfitted surgical mask, and attending physicians were (50\%) included in tuberculin skin-testing programs infrequently. In the 1996 resurvey, $103(76 \%)$ of 136 respondents returned a completed questionnaire. Of these, 99 (96\%) reported having rooms that met CDC criteria for acid-fast bacilli isolation. The N95 respiratory protective devices were used predominantly by healthcare workers, and attending physicians were increasingly (69\%) included in the hospitals' tuberculin skin-testing programs.

The authors concluded that most US hospitals are making progress in the implementation of CDC guidelines for preventing the transmission of $M$ tuberculosis. FROM Manangan LP, Simonds DN, Pugliese G, Kroc K, Banerjee SN, Rudnick JR, Steingraber K, Jarvis WR. Are US hospitals making progress in implementing guidelines for prevention of Mycobacterium tuberculosis transmission? Arch Intern Med 1998;158:1440-1444. 